\title{
BMJ Open Can education alter attitudes, behaviour and knowledge about organ donation? A pretest-post-test study
}

\author{
Donal McGlade, Barbara Pierscionek
}

To cite: McGlade D, Pierscionek B. Can education alter attitudes, behaviour and knowledge about organ donation? A pretest-post-test study. BMJ Open 2013;3: e003961. doi:10.1136/ bmjopen-2013-003961

- Prepublication history for this paper is available online. To view these files please visit the journal online (http://dx.doi.org/10.1136/ bmjopen-2013-003961).

Received 5 September 2013 Revised 14 November 2013 Accepted 27 November 2013

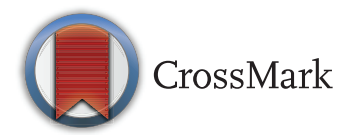

Faculty of Science, Engineering and Computing, Kingston University, Kingston upon Thames, Surrey, UK

Correspondence to

Professor Barbara

Pierscionek;

b.pierscionek@kingston.ac.uk

\section{ABSTRACT}

Objective: The emergence of evidence suggests that student nurses commonly exhibit concerns about their lack of knowledge of organ donation and

transplantation. Formal training about organ donation has been shown to positively influence attitude, encourage communication and registration behaviours and improve knowledge about donor eligibility and brain death. The focus of this study was to determine the attitude and behaviour of student nurses and to assess their level of knowledge about organ donation after a programme of study.

Design: A quantitative questionnaire was completed before and after participation in a programme of study using a pretest-post-test design.

Setting: Participants were recruited from a University based in Northern Ireland during the period from February to April 2011.

Participants: 100 preregistration nurses (female: male=96: 4) aged 18-50 years (mean (SD) 24.3 (6.0) years) were recruited.

Results: Participants' knowledge improved over the programme of study with regard to the suitability of organs that can be donated after death, methods available to register organ donation intentions, organ donation laws, concept of brain death and the likelihood of recovery after brain death. Changes in attitude postintervention were also observed in relation to participants' willingness to accept an informed system of consent and with regard to participants' actual discussion behaviour.

Conclusions: The results provide support for the introduction of a programme that helps inform student nurses about important aspects of organ donation.

\section{BACKGROUND}

Organ donation is a unique social activity that has a direct influence on the delivery of healthcare to a wide range of patients. Transplantation and its known therapeutic benefits are not possible without the cooperation and support of healthcare professionals, government and society as a whole. Transplantation is the treatment of choice that

\section{Strengths and limitations of this study}

- Its novelty, as this is the first UK-based study that highlights the importance of formal instruction and demonstrates the merits of knowledge gains in key areas related to organ donation and transplantation and the need for effective communication with family members.

- Findings were based on perceived knowledge rather than on actual knowledge and the use of self-reported measures to determine change in attitude and behaviour. It is based on a single cohort of student nurses.

- The study was conducted on an ethnically and socio-economically homogenous group.

improves life expectancy and quality of life. ${ }^{12}$ In addition, transplantation contributes to reducing healthcare expenditure. ${ }^{2-7}$ The donation and transplantation system represents a complex practice ${ }^{8}$ and is dependent on individual attitudes, social structures, cultural practices and religious beliefs. It is known that approximately $90 \%$ of the general public have a favourable view of organ donation. ${ }^{9}$ However, nurses have reported difficulties in being able to broach the subject of organ donation $^{10}{ }^{11}$ and as a consequence less than $55 \%$ of those likely to donate will be in a position to ultimately provide consent for donation. ${ }^{12}$ These inconsistencies serve to demonstrate that successful organ procurement fundamentally requires action on the part of the healthcare professional. Therefore, the attitude and approach of those healthcare professionals who procure organs for transplantation should not be dismissed as inconsequential. Nurses represent the largest group of such professionals ${ }^{13}$ and are the critical link within the transplantation system. ${ }^{14}$ Although it is recognised that not all nurses would be in a position to initiate the organ donation process, evidence suggests that nurses recognise that they have a crucial role to play in helping to support the process of organ 
donation and transplantation and in helping to raise its profile among the public. ${ }^{15} 16$

The emergence of evidence tends to suggest that nurses commonly exhibit concerns about their lack of knowledge and experience in dealing adequately with all aspects of organ donation and transplantation. ${ }^{10} 11$ 17-24 It has been found that medical students possess limited knowledge about organ donation. ${ }^{25-27}$ This is likely to be because of the way in which organ donation and transplantation training is being delivered in a non-systematic manner from within other subjects. ${ }^{28}$ It has been noted that student nurses based in the USA frequently misunderstand the concept of brain death ${ }^{29}$ and that important issues related to brain death and cardiac death continue to be neglected. ${ }^{28}$ It has also been shown that there is a paucity of knowledge about how to initiate discussion about organ donation. ${ }^{28}$

It has been acknowledged that formal training about organ donation can successfully influence student nurses' attitudes, encourage communication and registration behaviours and help improve knowledge about donor eligibility and brain death. ${ }^{30-32}$ Further improving knowledge about the organs suitable for donation, the methods available for registration and the regulations that govern the process of organ donation in the UK could help remove significant barriers and encourage engagement in prosocial behaviours. ${ }^{33}$ It is therefore important to ensure that those who may influence rates of transplantation are prepared and properly informed about the processes involved.

The objective of this study was to examine the attitudes and behaviour of student nurses and to assess their level of knowledge about organ donation before and after a programme of study. It is hypothesised that a programme of study can significantly improve knowledge and positively influence attitude and behaviour towards organ donation.

\section{METHODS}

\section{Design}

A pretest-post-test design was chosen to establish the impact of a programme of study on knowledge, attitude and behaviour involving two sets of cross-sectional data on the same population.

\section{Ethics}

The researcher (DM) visited the university prior to starting the study so that background information could be provided and to help resolve any queries. Participation in the study was voluntary and without any form of compensation. Informed consent was obtained from all participants.

\section{Setting and participants}

Convenience sampling techniques were used to recruit preregistered nursing students undertaking a full-time degree course leading to the award of BSc (Hons).
A total of 115 second year students were approached during the third trimester of a 3-year course of education at the University of Ulster, Northern Ireland. This sample was chosen because the population of Northern Ireland is relatively homogenous in terms of ethnicity, religion and socioeconomic factors. The cohort had recently completed a considerable proportion of their elective placements in general and specialist hospital care.

\section{Measures}

The questionnaire

The participants completed a quantitative questionnaire based on previous validated frameworks. ${ }^{34-38}$ The questionnaire was further developed by several academic experts in the areas of biomedical science, mathematics and psychology and was extended to include additional concepts: attitude to registration and donation, knowledge about brain death, financial incentives and legislation. The questionnaire was then tested on a student nursing population in Northern Ireland and took into consideration the appropriateness of the content, use of language and sequence of questions. The questionnaire gathered demographic information on gender, age, country of birth, marital status and religious affiliation. Items in the questionnaire were categorised as two behaviour items, one willingness item, eight attitude items and six knowledge items (box 1).

\section{The programme of study}

The participants completed a $33 \mathrm{~h}$ programme of study within the degree course that incorporated important issues relating to the clinical care of the potential organ donor as well as from the perspective of the transplant patient. The programme was designed to place an emphasis on the following areas: criteria for organ donation and what organs can be donated, nursing the potential organ donor and transplant patient and areas of potential risk, procedures involved in neurological assessment and management of brain injury, medical diagnosis of brain death, the legally accepted definition that leads to certification of death, effective communication strategies with donors and their relatives as well as recipients and their relatives, processes involved in procurement of organs and ethical aspects of organ donation and transplantation such as reasons for consent, respect for autonomy, beneficence and confidentiality. The importance of discussing intention to donate with family members was also covered. The programme of study was delivered to participants in a classroom setting with the whole student cohort gathered at the same time.

\section{Data collection and analysis}

Data were collected within an hour of start of the programme of study (February 2011) and after completion of the programme of study (April 2011). To determine whether the sample size chosen was adequate, a post 


\section{Box 1 Questionnaire items}

\section{Behaviour}

1. Have you registered to be an organ donor? ${ }^{34}$ (yes/no)

2. Have you discussed your organ donation intentions with your family? ${ }^{34}$ (yes/no)

Willingness

1. Would you consider becoming an organ donor? (yes/no/l do not know)

Attitude

1. Becoming an organ donor makes me think about my own death $^{34}$ (strongly agree/agree/disagree/strongly disagree)

2. What do you think are the benefits of donation ${ }^{34} 38$ (to help improve another person's quality of life/to save another person's life/to help families through the grieving process/it is a good thing for society)

3. By signing a donor card, doctors might do something to me before I am really dead ${ }^{34} 36$ (strongly agree/agree/disagree/ strongly disagree)

4. The possible misuse of my organs after death makes me feel less supportive of organ donation ${ }^{38}$ (strongly agree/agree/disagree/strongly disagree)

5. I would support a change to the current organ donation system $^{36}$ (strongly agree/agree/disagree/strongly disagree)

6. The law should be changed so that everyone is an organ donor unless they say no ${ }^{34}{ }^{37}$ (strongly agree/agree/disagree) strongly disagree)

7. The law should be changed so that everyone is encouraged to formalise their donation intentions (strongly agree/agree/disagree/strongly disagree)

8. The government should provide financial help to those families who donate (strongly agree/agree/disagree/strongly disagree)

Knowledge

1. Of which method of registration are you aware? ${ }^{35}$ (donor card/ national register/driving license/general practitioner surgery/ electoral roll/passport/Boots The Chemist)

2. Which of the following do you think can be donated after death $?^{38}$ (eyes/heart/kidneys/liver/lungs)

3. Does your religion allow organ donation? ${ }^{34}{ }^{38}$ (yes/no/l do not know)

4. Are you aware of any laws that control organ donation? ${ }^{38}$ (yes/no/l do not know)

5. Would you consider a person who is declared brain dead but still has a beating heart as being dead? ${ }^{36}$ (yes/no/l do not know)

6. How likely do you think it is that a brain dead person with a beating heart might recover and live $?^{34}$ (very likely/likely/ unlikely/very unlikely) hoc power analysis was conducted. The Exact tests option was chosen from the test family and two dependent groups (McNemar) selected as the statistical test in $\mathrm{G}^{*}$ Power V.3.17. The power analysis demonstrated that the sample size $(n=100)$ had an acceptable level of power (0.89) and was deemed adequate for the analysis. $^{39}$

Descriptive statistics were used to assess demographic information, with the McNemar test chosen as the most appropriate tool for analysing dichotomous items from matched pairs of participants ${ }^{40}$ using the Statistical Package for Social Sciences (SPSS) V.19. It was decided that Yates' correction for continuity should not be applied within a two-by-two contingency table. This is based on evidence suggesting that the corrected $\chi^{2}$ statistic is overly conservative and that the conventional statistic will provide adequate control over type I errors. ${ }^{41} 42$ A significant McNemar $\chi^{2}$ is an indication of a change between baseline and follow-up measurement.

\section{RESULTS}

Initially, 109 participants completed a questionnaire at baseline. Of these participants, 100 (91.7\%) also completed a follow-up questionnaire; $9(8.3 \%)$ failed to do so and were subsequently excluded from any further analysis. The final response rate was $87 \%$.

Of the participants who completed both questionnaires, 96 were women which reflects the gender base of the profession. ${ }^{43}$ Ages ranged from 18 to 50 years (mean (SD) 24.3 (6.0) years). The majority of participants $(n=82)$ were in their third decade, 5 in their second decade, 10 in their fourth decade, 1 in their fifth decade and 2 in their sixth decade. All participants reported religious (Christian) beliefs.

\section{Knowledge about organ donation}

Responses obtained from participants demonstrated significant changes in several key areas as seen in table 1. Knowledge about the suitability of organs that can be donated after death improved considerably (McNemar $\chi^{2}=23.059$, exact $\left.\mathrm{p}<0.001\right)$ with $28 \%$ more participants able to correctly identify which organs are suitable for donation at follow-up compared with baseline measurement (95\% CI 17.5 to 38.1). In particular, there was an improvement of knowledge in relation to the donation

\section{Table 1 Knowledge about organ donation}

\section{Percentage of participants}

1. Who answered correctly the methods for organ donor registration

2. Who answered correctly the organs that can be donated after death

3. Who answered correctly that their religion allows organ donation

4. Aware of laws that control organ donation

5. Who answered correctly that a person declared brain dead is legally dead

6. Who answered correctly that a brain dead person is unlikely to recover and live
Total sample, $\mathbf{n}(\%)$

\begin{tabular}{cccc}
\hline Pretest & Post-test & p Value \\
\hline $18(18.0)$ & $42(42.0)$ & $<0.001$ \\
$67(67.0)$ & $95(95.0)$ & $<0.001$ \\
$82(82.0)$ & $88(88.0)$ & 0.157 \\
$5(5.0)$ & $21(21.0)$ & 0.001 \\
$14(14.0)$ & $31(31.0)$ & 0.001 \\
$77(77.0)$ & $89(89.0)$ & 0.019 \\
\hline
\end{tabular}


Table 2 Willingness and behaviour towards organ donation

\begin{tabular}{lllr}
\hline & \multicolumn{1}{l}{ Total sample, $\mathbf{n}(\%)$} & Post-test & P Value \\
\cline { 2 - 4 } Percentage of participants & Pretest & $38(38.0)$ & 0.132 \\
\hline 1. Registered to be an organ donor & $33(33.0)$ & $45(45.0)$ & 0.086 \\
2. Considering becoming an organ donor & $35(35.0)$ & $53(53.0)$ & $<0.001$ \\
3. That discussed donation with their family & $39(39.0)$ & . & \\
\hline
\end{tabular}

of corneal tissue: $96 \%$ of participants correctly understood at follow-up that the cornea is a tissue that can be successfully donated after death, compared with $72 \%$ at baseline (McNemar $\chi^{2}=19.200$, exact $\mathrm{p}<0.001 ; 95 \%$ CI 15.3 to 32.4 ). There was an increase of $24 \%$ in the number of participants who understood the methods available to register organ donation intentions subsequent to baseline measurement (McNemar $\chi^{2}=24.000$, exact $\mathrm{p}<0.001 ; 95 \%$ CI 15.3 to 32.4 ).

Following completion of the study, there was a rise in the number of participants who understood the laws relating to organ donation (McNemar $\chi^{2}=11.636$, exact $\mathrm{p}=0.001 ; 95 \%$ CI 7.0 to 25.3 ) and a statistically significant improvement in knowledge about brain death (McNemar $\chi^{2}=11.560$, exact $\mathrm{p}=0.001 ; 95 \%$ CI 7.5 to 26.4) and the likelihood of recovery following a diagnosis of brain death (McNemar $\chi^{2}=5.538$, exact $\mathrm{p}=0.019$; $95 \%$ CI 1.9 to 22.0 ; table 1$)$. However, $11 \%$ of the cohort continued to express doubts about this matter and believed that a person declared brain dead might subsequently recover and lead a normal life.

No statistically significant change was found with regard to religion and its supporting role in organ donation (McNemar $\chi^{2}=2.000$, exact $\mathrm{p}=0.157$; table 1 ). Responses did not differ on the basis of willingness to register as an organ donor.

\section{Willingness and behaviour towards organ donation}

The number of participant's willing to register as an organ donor rose by $14.3 \%$ (baseline: 35 willing, 13 unwilling, 22 unsure; follow-up: 45 willing, 7 unwilling, 18 unsure). Participants also reported a $5 \%$ rise in the number currently registered (baseline: 33 willing, 67 unwilling; follow-up: 38 willing, 62 unwilling). However, the observed increases were not statistically significant. At follow-up, a greater number of participants (14\%; $95 \%$ CI $6.9 \%$ to $20.8 \%$ ) indicated that they had discussed their organ donation intentions with their family or friends compared with baseline measurement $\left(\right.$ McNemar $\chi^{2}=14.000$, exact $\mathrm{p}<0.001$; table 2$)$.

\section{Attitude towards organ donation}

A greater number of participants $(16 \%$; $95 \%$ CI $4.7 \%$ to $26.8 \%$ ) favoured an informed system of consent at follow-up rather than opting for a change in legislation (McNemar $\chi^{2}=7.529$, exact $\mathrm{p}=0.006$; table 3$)$. The results indicate that the majority of participants at baseline $(72 \%)$ and follow-up $(70 \%)$ associated the process of registering as an organ donor with recognition of their own mortality and that support for the introduction of a government incentive scheme was low (baseline: 28\%; follow-up: 27\%; table 3). No statistically significant change was found with regard to perceived benefits of organ donation (McNemar $\chi^{2}=2.000$, exact $\mathrm{p}=0.157$ ); medical distrust (McNemar $\chi^{2}=0.000$, exact $\mathrm{p}=1.000$ ) and misappropriation of donated organs (McNemar $\chi^{2}=0.100$, exact $\mathrm{p}=0.752$; table 3 ). The responses did not differ on the basis of willingness to register as an organ donor.

\section{DISCUSSION}

The results from this study support the conclusions of previous work that student nurses' knowledge of organ donation can be substantially improved and that their discussion behaviours could be positively influenced by

Table 3 Attitude towards organ donation

\begin{tabular}{|c|c|c|c|}
\hline \multirow[b]{2}{*}{ Percentage of participants } & \multicolumn{2}{|c|}{ Total sample, $\mathbf{n}(\%)$} & \multirow[b]{2}{*}{ p Value } \\
\hline & Pretest & Post-test & \\
\hline 1. Who thought that organ donation makes them think about their own death & $72(72.0)$ & $70(70.0)$ & 0.695 \\
\hline 2. Who answered correctly the benefits of donation & $87(87.0)$ & $93(93.0)$ & 0.157 \\
\hline $\begin{array}{l}\text { 3. Who thought that by signing a donor card, doctors might do something to them before } \\
\text { they were really dead }\end{array}$ & $17(17.0)$ & $17(17.0)$ & 0.100 \\
\hline 4. Who felt less supportive of organ donation because their organs might be misused & $53(53.0)$ & $51(51.0)$ & 0.752 \\
\hline 5. Who would support a change to the current organ donation system & $80(80.0)$ & $64(64.0)$ & 0.006 \\
\hline 6. Who thought the law should be changed so everyone is a donor unless they say no & $43(43.0)$ & $48(48.0)$ & 0.336 \\
\hline $\begin{array}{l}\text { 7. Who thought the law should be changed so everyone is encouraged to formalise their } \\
\text { donation intentions }\end{array}$ & $79(79.0)$ & $74(74.0)$ & 0.369 \\
\hline 8. Who thought the government should provide financial help to families who donate & $28(28.0)$ & $27(27.0)$ & 0.835 \\
\hline
\end{tabular}


education about the topic. ${ }^{30-32}$ Statistically significant changes in knowledge about fundamental aspects of organ donation occurred in relation to the suitability of organs that could be donated after death, methods available to register organ donation intentions and organ donation laws and the likelihood of recovery following a diagnosis of brain death. Particularly notable were the improvements in understanding the fundamental medico-legal issues, namely how the law operates with regard to donation, the difference between informed and presumed consent and the fact that brain death is legally certifiable cause of death. Previous studies ${ }^{30-32}$ have suggested that education plays an important role in helping to influence attitude. It was notable, in this study that post-test, the only significant change in attitude was a decrease in the number of participants who favoured a change in the law from the current system of informed consent to one of presumed consents.

There was an increase in awareness of the benefits of organ donation but this was not significant as a high proportion of participants at baseline $(87 \%)$ expressed such awareness. There was very little change, if any, with regard to associating organ donation with a hastened death (attitude 3, table 3), fear of organ misuse (attitude 4 , table 3 ) or opinion about financial assistance (attitude 8 , table 3$)$.

Education about organ donation is not routinely incorporated in nursing degree curricula. ${ }^{28} \mathrm{~A}$ course of study needs to be objective and sufficiently informative to encourage independent thought that will lead to measured decisions to donate and can be conveyed with justification to relatives. The "Spanish Model of Organ Donation and Transplantation" has been accredited with the highest rate of deceased organ donation for a whole country. ${ }^{44}$ This model provides education to healthcare professionals, helping them to engage fully with organ donation and transplantation and has directly resulted in a continuous rise in the number of families willing to provide consent to donation. ${ }^{45}$

It needs to be recognised that while the individual decision whether or not to donate should be paramount, in many cases the final decision rests with relatives. Indeed, the most common reason for lack of organ donation is a failure to obtain consent from relatives of the potential donor. ${ }^{46}$ This is attributed to families not being made fully aware of the prior wishes of the deceased. ${ }^{47-49}$ Communicating an intention to donate to family members is frequently omitted.$^{50} 51$ This may be the reason that over half of all families approached for organ donation in the UK typically refuse to provide consent. ${ }^{12}$ The importance of effective communication was addressed in this programme of study, with results indicating that participants were more likely to engage in discussion about organ donation with family members after the programme was completed. The programme may have directly motivated such discussions or it could be that other emotive aspects, encountered during the course of study, may have prompted such discourse.
This study has shown that even within a small group, after a programme of study, the understanding about organ donation and the processes involved can be significantly improved, leading to consideration about donation of organs and decisions with relatives. This study aimed to capture any changes in knowledge and attitudes immediately after a programme of study and to determine whether there would be a concomitant response in organ donation registration and discussion behaviours. Registration rates of the participants before starting the study were akin to those of the general population ${ }^{12}$ suggesting that choice of a caring vocation such as nursing does not necessarily equate with a greater degree of altruism with respect to organ donation. This observation that many healthcare professionals do not always exhibit prodonation behaviours has been reported previously. ${ }^{17-24}$ A considerable proportion of participants indicated that they associated registering as an organ donor with issues of mortality and this may help explain the relatively low level of donation. It has been suggested that the exhibition of unusually high levels of fear or anxiety about death can prevent people from associating themselves with a behaviour that requires them to consider their own mortality. ${ }^{52-54}{ }^{55}$ It should also be noted that the cohort in this study was relatively young and would be less likely to have encountered life-threatening situations or serious illness. There were too few participants in the older age groups to assess any trends with age.

The concept of brain death and what constitutes the legal definition of death has been frequently misunderstood by healthcare professionals. ${ }^{11}{ }^{17}{ }^{19-22}$ The results show that participants' understanding of brain death and the likelihood of recovery following a diagnosis of brain death improved significantly on completion of the study. Although this is a promising result, a small proportion of the participants, nevertheless, continued to raise concerns about their understanding of this important concept. Correctly understanding brain death and the likelihood of recovery is paramount in the organ donation process to ensure that misconceptions are avoided and that relatives of the deceased can be properly informed to make confident end-of-life decisions. ${ }^{47} 5657$

The results demonstrate that prior to the programme of study, around one-third of the participants did not understand which organs could be successfully donated after death and this was most pertinent in relation to the donation of corneal tissue-an organ that is not donated to save life but to restore sight. The programme of study improved understanding significantly. Less than a fifth of participants were aware of the many different methods that exist to register organ donation intentions in the UK before the programme; while this improved after completion of the programme, less than half of the cohort (42\%) exhibited sufficient knowledge in this area. The increase in knowledge may have had an effect on attitude, as after the programme of study a greater number of participants were unwilling to support 
changes to legislation and favoured the current system of informed consent. This notwithstanding, the majority (64\%) of the participants supported changes to the organ donation system in the UK.

The majority of the participants in this study disapproved of a financially incentivised rewards scheme and this did not alter after the programme of study. This effect has been reported previously ${ }^{35}$ and is thought to be because financial payments appear to undermine the individual and cast doubt over their intentions to donate. ${ }^{58}$

This study used a pretest-post-test design. The limitations of such a design are that the pretest may sensitise participants to what is being investigated and thereby affect post-test results. In this research, the intervention was a programme of study aimed at informing and teaching participants and hence the post-test was to determine what had been learned and understood and how this may alter attitudes and behaviour. Given that the participants will have been aware that they would be asked to complete a questionnaire after the programme of study, they may have paid more attention to the course content, than they otherwise would have done. The short duration between the intervention and the pretesting and post-testing minimised the effects of any external factors that could have occurred between testing and the programme. However, as the programme took place over a period of 2 months, there may have been influences from media or other social or community sources that participants encountered between lectures that had some effect on the post-test results.

More insight into the benefits of such courses will be gained by investigating a wider diversity of cohorts and trialling longer courses of study so that participants have a longer period of time to consider whether to register for organ donation. As this study utilised a convenience sample to recruit participants from a single institution, the findings cannot be generalised to other nursing students from the UK.

\section{CONCLUSION}

A short programme of study can effectively improve student nurses' knowledge of organ donation and positively influence their ability to discuss organ donation intentions with their family. The effect of education, whether concentrated and provided over a shorter period or given as a smaller component of a course emphasising various aspects of organ donation and procurement, needs to be tested with different cohorts from various parts of the UK. This will help determine whether providing appropriate education to those who will be involved in procuring organs for transplantation can influence the number and types of organs that are donated.

Acknowledgements The authors would like to acknowledge the assistance of Dr Carol McClenahan and Dr Pauline Black for their invaluable support throughout the study.
Contributors DM and BP conceived and designed the experiments, analysed the data, contributed in materials/analysis tools and wrote the article. BP is the guarantor.

Funding This research received no specific grant from any funding agency in the public, commercial or not-for-profit sectors.

\section{Competing interests None.}

Ethics approval Approval was sought and subsequently granted from the Institutional Review Board at the University of Ulster Ethics Filter Committee.

Provenance and peer review Not commissioned; externally peer reviewed.

Data sharing statement No additional data are available.

Open Access This is an Open Access article distributed in accordance with the Creative Commons Attribution Non Commercial (CC BY-NC 3.0) license, which permits others to distribute, remix, adapt, build upon this work noncommercially, and license their derivative works on different terms, provided the original work is properly cited and the use is non-commercial. See: http:// creativecommons.org/licenses/by-nc/3.0/

\section{REFERENCES}

1. Evans RW, Manninen DL, Garrison LP, et al. The quality of life of patients with end-stage renal disease. N Engl J Med 1985;312: 553-9.

2. Fiebiger W, Mitterbauer C, Oberbauer R. Health-related quality of life outcomes after kidney transplantation. Health Qual Life Outcomes 2004;2:2.

3. Haller M, Gutjahr G, Kramar R, et al. Cost-effectiveness analysis of renal replacement therapy in Austria. Nephrol Dial Transplant 2011;26:2988-95.

4. Howard K, Salkeld G, White S, et al. The cost-effectiveness of increasing kidney transplantation and home-based dialysis. Nephrology 2009;14:123-32.

5. Maynard A. Developing the healthcare market. Econ J 1991;101: 1277-86.

6. Mendeloff $\mathrm{J}, \mathrm{Ko} \mathrm{K}$, Roberts MS, et al. Procuring organ donors as a health investment: how much should we be willing to spend? Transplantation 2004;78:1704-10.

7. NHSBT. Cost-effectiveness of transplantation. Bristol: NHSBT, 2009.

8. McGlade D, Rae G, McClenahan C, et al. Regional and temporal variations in organ donation (secondary analyses of databases). BMJ Open 2011;1:e000055.

9. Organ Donation Taskforce. Organs for transplants: a report from the Organ Donation Taskforce. London: Department of Health, 2008.

10. Ozdag N. The nurses knowledge, awareness and acceptance of tissue-organ donation. EDTNA ERCA J 2001;27:201-6.

11. Smith $\mathrm{M}, \mathrm{McGee} \mathrm{H}$. Organ donation services in Ireland: current situation and future prospects. Dublin: Royal College of Surgeons in Ireland, 2004.

12. NHSBT. Organ donation and transplantation: activity report 2011/12. Bristol: NHSBT, 2012.

13. The Health and Social Care Information Centre. NHS workforce: summary of staff in the NHS: results from September 2012 census. Leeds: The Health and Social Care Information Centre, 2013.

14. Ertin $\mathrm{H}$, Harmanci AH, Mahmutoglu FS, et al. Nurse-focussed ethical solutions to problems in organ transplantation. Nurs Ethics 2010;17:705-14.

15. Cebeci F, Sucu G, Karazeybek E. The role of nurses to augment organ donation and transplantation: a survey of nursing students. Transplant Proc 2011;43:412-14.

16. Lin LM, Lin CC, Lam HD, et al. Increasing the participation of intensive care nurses to promote deceased donor organ donation. Transplant Proc 2010;42:716-18.

17. Akgün HS, Bilgin N, Tokalak I, et al. Organ donation: a cross-sectional survey of the knowledge and personal views of Turkish health care professionals. Transplant Proc 2003;35:1273-5.

18. Bener A, El-Shoubaki H, Al-Maslamani Y. Do we need to maximise the knowledge and attitudes level of physicians and nurses towards organ donation and transplant? Exp Clin Transplant 2010;6:249-53.

19. Demir T, Selimen D, Yildirim M, et al. Knowledge and attitudes towards organ/tissue donation and transplantation among health care professionals working in organ transplantation or dialysis units. Transplant Proc 2011;43:1425-8.

20. Duke J, Murphy B, Bell A. Nurses' attitudes towards organ donation: an Australian perspective. Dimens Crit Care Nurs 1998;17:264-70. 
21. Flodén A, Forsberg A. A phenomenographic study of ICU-nurses' perceptions of and attitudes to organ donation and care of potential donors. Intensive Crit Care Nurs 2009;25:306-13.

22. Molzahn AE. Knowledge and attitudes of critical care nurses regarding organ donation. Can J Cardiovasc Nurs 1997;8:13-18.

23. Wight $\mathrm{C}$, Cohen $\mathrm{C}$, Beasley $\mathrm{C}$, et al. Donor action: a systematic approach to organ donation. Transplant Proc 1998;30:2253-4.

24. Zambudio AR, Martínez-Alarcón L, Parrilla P, et al. Attitude of nursing staff toward organ donation in a Spanish hospital with a solid-organ transplant program. Prog Transplant 2009;19:371-7.

25. Bardell T, Hunter DJW, Kent WDT, et al. Do medical students have the knowledge needed to maximize organ donation rates? Can $\mathrm{J}$ Surg 2003;46:453-7.

26. Edwards TM, Essman C, Thornton JD. Assessing racial and ethnic differences in medical student knowledge, attitudes and behaviors regarding organ donation. J Natl Med Assoc 2007;99:131-7.

27. Essman C, Thornton J. Assessing medical student knowledge, attitudes and behaviors regarding organ donation. Transplant Proc 2006;38:2745-50.

28. Anker AE, Feeley $\mathrm{TH}$, Friedman $\mathrm{E}$, et al. Teaching organ and tissue donation in medical and nursing education: a needs assessment. Prog Transplant 2009;19:343-8.

29. Garde PP, Corbett NA. Organ donation: knowledge and attitudes of nursing and college students. J Transpl Coord 1994;4:48-52.

30. Kiberd C. Curriculum effect on nursing students' attitudes and knowledge towards organ donation and transplantation. ANNA J 1998;25:210-16.

31. López-Montesinos MJ, Manzanera Saura JT, Mikla M, et al. Organ donation and transplantation training for future professional nurses as a health and social awareness policy. Transplant Proc 2010;42:239-42.

32. Abbasi Dolatabadi Z, Farahani B, Fesharaki M, et al. Effect of education about brain death and organ donation on attitude and knowledge of nursing students. Iran J Crit Care Nurs 2010;3:109-12.

33. Bandura A. Exercise of personal and collective efficacy in changing societies. In: Bandura A. ed. Self-efficacy in changing societies. Cambridge: Cambridge University Press, 1995:1-45.

34. Conesa C, Ríos A, Ramírez $\mathrm{P}$, et al. Psychosocial profile in favour of organ donation. Transplant Proc 2003;35:1276-81.

35. Haddow G. "Because you're worth it?" The taking and selling of transplantable organs. J Med Ethics 2006;32:324-8.

36. Kent BC, Owens RG. Conflicting attitudes to corneal and organ donation: a study of nurses' attitudes towards organ donation. Int $J$ Nurs Stud 1995;32:484-92.

37. Rodrigue JR, Cornell DL, Howard RJ. Attitudes towards financial incentives, donor authorization, and presumed consent among next-of-kin who consented vs. refused organ donation. Transplantation 2006;81:1249-56.

38. Saleem T, Ishaque S, Habib N, et al. Knowledge, attitudes and practices survey on organ donation among a selected adult population of Pakistan. BMC Med Ethics 2009;10:5
39. Cohen J. Statistical power analysis. Curr Dir Psychol Sci 1992;1:98-101.

40. Brace N, Kemp R, Snelgar R. Tests for nominal data. In: SPSS for psychologists. 3rd edn. Hampshire: Palgrave Macmillan, 2006:127-30

41. Haviland M. Yate's correction for continuity and the analysis of $2 \times 2$ contingency tables. Stat Med 1990;9:363-7.

42. Thompson B. Misuse of chi-square contingency-table test statistics. Educ Psychol Res 1988;8:39-49.

43. Nursing and Midwifery Council. Statistical analysis of the register 1 April 2007 to 31st March 2008. London: Nursing and Midwifery Council, 2008.

44. Matesanz R, Dominguez-Gil B. Strategies to optimize deceased organ donation. Transplant Rev 2007;21:177-88.

45. Matesanz R. International figures on donation and transplantation2009. Madrid: Council of Europe, 2011.

46. Simpkin AL, Robertson LC, Barber VS, et al. Modifiable factors influencing relatives' decision to offer organ donation: systematic review. BMJ 2009;338:b991.

47. Anker AE, Feeley TH. Why families decline donation: the perspective of organ procurement coordinators. Prog Transplant 2010;20:239-46.

48. New $\mathrm{B}$, Solomon $\mathrm{M}$, Dingwall $\mathrm{R}$, et al. A question of give and take. Improving the supply of donor organs for transplantation. London: King's Fund Institute, 1994; (Report Number 18).

49. Siminoff LA, Gordon N, Hewlett J, et al. Factors influencing families' consent for donation of solid organs for transplantation. JAMA 2001;286:71-7.

50. McDonald DD, Ferreri R, Jin C, et al. Willingness to communicate organ donation intention. Public Health Nurs 2007;24:151-9.

51. Newton JD, Burney S, Hay M, et al. A profile of Australian adults who have discussed their posthumous organ donation wishes with family members. J Health Commun 2010;15:470-86.

52. Besser A, Amir M, Barkan S. Who signs an organ transplant card? A study of personality and individual differences in a sample of Israeli university students. Pers Individual Differences 2004;36:1709-23.

53. Lester D. Organ donation and the fear of death. Psychol Rep 2005;96:769-70.

54. Robbins RA. Signing an organ donor card: psychological factors Death Stud 1990;14:219-29.

55. Horton RL, Horton PJ. A model of willingness to become a potential organ donor. Soc Sci Med 1991;33:1037-51.

56. DeJong W, Franz HG, Wolfe SM, et al. Requesting organ donation an interview study of donor and nondonor families. Am J Crit Care 1998:7:13-23.

57. Siminoff LA, Mercer MB, Arnold R. Families' understanding of brain death. Prog Transplant 2003;13:218-24.

58. Bénabou R, Tirole J. Incentives and prosocial behavior. Am Econ Rev 2006;96:1652-78. 